\title{
EFEITO DA FRAÇÃO MOLAR NA CINÉTICA DE ADSORÇÃO BICOMPOSTO DE ÍONS PRATA E COBRE EM ARGILA BENTONÍTICA
}

\author{
A.C. R. do CARMO, E. D. de FREITAS, A. F. de ALMEIDA NETO e M. G. A. VIEIRA
}

Universidade Estadual de Campinas, Faculdade de Engenharia Química

E-mail para contato: melissagav@feq.unicamp.br

\begin{abstract}
RESUMO - Novos métodos de remoção de metais pesados presentes em efluentes tem sido cada vez mais estudados devido a crescente preocupação com a preservação ambiental. Tendo isto em vista, o presente trabalho estudou o efeito da fração molar na cinética de adsorção dos íons prata e cobre em solução bicomposta, em argila bentonítica Verde-lodo. Os ensaios envolveram cinética em banho finito, especiação metálica e estudo do $\mathrm{pH}_{\mathrm{ZPC}}$ do adsorvente. Foi observado que um tempo de 400 minutos foi necessário para que se atingisse um equilíbrio, e que o cobre foi adsorvido em maior quantidade que a prata. Também foi observado que no $\mathrm{pH}$ trabalhado, o adsorvente está positivamente carregado.
\end{abstract}

\section{INTRODUÇÃO}

A poluição aquática é um grande problema, pois altera as características físicas, químicas e biológicas da água, prejudicando sua qualidade e impossibilitando seu uso para consumo humano. Uma das formas de contaminação é a emissão de metais pesados, cujas principais fontes de poluição são provenientes de efluentes industriais, de mineração e das lavouras. $\mathrm{O}$ que torna esse tipo de poluição ainda mais preocupante é o chamado efeito de Amplificação Biológica, onde os metais pesados, por serem armazenados nos organismos vivos, se acumulam ao longo da cadeia alimentar. Dessa forma, o Conselho Nacional do Meio Ambiente (CONAMA) estabelece os valores máximos permitidos de metais pesados presentes em determinado efluente (Aguiar et al., 2002).

A remoção de metais pesados de efluentes aquáticos envolve processos físicoquímicos de precipitação, troca iônica, adsorção e extração por solventes, sendo a precipitação química o método mais utilizado. Porém, a utilização de algumas técnicas tradicionais para a descontaminação de grandes volumes de efluentes com baixas concentrações de metais pesados é inadequada. Como alternativa, métodos como a eletrodiálise, a osmose reversa, a ultrafiltração e a adsorção em materiais naturais, que promovam a retenção seletiva e reversível de cátions metálicos, têm sido cada vez mais investigadas (Jimenez et al., 2004).

\section{MATERIAL E MÉTODOS}

A argila Verde-lodo, proveniente da cidade de Boa Vista-PB, fornecida em sua forma bruta pela Dolomil Ltda., foi moída e peneirada, a fim de se obter granulação média de 0,855 $\mathrm{mm}$. O material foi em seguida submetido a um processo de calcinação a $500{ }^{\circ} \mathrm{C}$ por 24 horas em um forno mufla. De acordo com Almeida Neto (2011), esta é uma etapa importante, pois garante um aumento na estabilidade mecânica do adsorvente. 
O ensaio de cinética foi realizado para três soluções diferentes proporções de frações molares dos íons metálicos, sendo que as concentrações de prata e cobre (em $\mathrm{mmol} / \mathrm{L})$ de cada uma foram, respectivamente: 1,0 e 1,0 (Solução 1); 1,5 e 0,5 (Solução 2) e 0,5 e 1,5 (Solução 3). As soluções foram obtidas por meio da pesagem e dissolução em água desionizada de nitrato de prata e de nitrato de cobre tri-hidratado. Para o procedimento, 1 litro de solução foi colocado em um béquer, ficando submetida a agitação constante e, em seguida, 10 gramas de adsorvente foram adicionados. O controle do tempo foi feito utilizando um cronômetro e, em intervalos de tempo previamente determinados, $3,5 \mathrm{~mL}$ de amostra foram retirados com o auxílio de uma pipeta automática. Foi tomado o cuidado para que o volume total retirado não ultrapassasse $8 \%$ do volume inicial, de forma a não alterar a concentração da solução. A alíquota retirada era então submetida a uma centrifugação, a $4000 \mathrm{rpm}$ durante 10 minutos e a concentração do sobrenadante era determinada através de um espectrofotômetro de absorção atômica.

A concentração do íon metálico (q) em função do tempo (t) pode ser calculada segundo a Equação 1:

$$
q(t)=\frac{V}{m}(C o-C(t))
$$

sendo $\mathrm{V}$ o volume em litros da solução no béquer, $\mathrm{m}$ a massa de adsorvente em gramas, Co a concentração inicial do íon metálico na solução em mmol/L e $\mathrm{C}(\mathrm{t})$ a concentração do íon metálico na solução no instante $\mathrm{t}$, também em mmol/L.

As curvas cinéticas foram tratadas utilizando-se o modelo de pseudoprimeira ordem, modelo de pseudossegunda ordem, difusão intrapartícula e modelo de Boyd, com os ajustes realizados pelo programa Origin 6.0.

Para a obtenção do valor do $\mathrm{pH}_{\mathrm{ZPC}}$ do adsorvente, foi realizada uma titulação potenciométrica onde, primeiramente, em 2 amostras de $10 \mathrm{~g}$ de argila já contaminadas com os metais, foram adicionados $100 \mathrm{~mL}$ de solução de Acetato de Amônio $\left(\mathrm{CH}_{3} \mathrm{COONH}_{4}\right)$ 0,1 $\mathrm{mol} / \mathrm{L}$, o qual atua como eletrólito, e o $\mathrm{pH}$ inicial (após o equilíbrio ter sido atingido) foi determinado. Em seguida, titulou-se uma das amostras com solução de ácido acético $\left(\mathrm{CH}_{3} \mathrm{COOH}\right)$ 0,3 mol/L e a outra com solução de hidróxido de amônio $\left(\mathrm{NH}_{4} \mathrm{OH}\right)$ 0,25 mol/L, anotando-se o volume adicionado de titulante correspondente a cada variação no valor do $\mathrm{pH}$.

Foi possível determinar a carga superficial do sólido (S) por meio da Equação 2:

$$
S=\frac{\mathrm{Ca}-\mathrm{Cb}+\left[\mathrm{OH}^{-}\right]-\left[\mathrm{H}^{+}\right]}{\mathrm{Cm}}
$$

sendo $\mathrm{Ca}$ a concentração do ácido corrigida (mol/L), $\mathrm{Cb}$ a concentração de base corrigida $(\mathrm{mol} / \mathrm{L})$ e $\mathrm{Cm}$ a concentração de sólido em suspensão $(\mathrm{g} / \mathrm{L})$. Dessa forma, obteve-se um gráfico de densidade de carga em função do $\mathrm{pH}$ e encontrou-se o valor do $\mathrm{pH}_{\mathrm{ZPC}}$, ponto onde curva cruza o eixo das abscissas e que corresponde a densidade de carga igual a zero. $\mathrm{O}$ valor de densidade de carga foi obtido multiplicando o valor de $\mathrm{S}$ pela constante de Faraday e dividindo pela área superficial.

\section{RESULTADOS E DISCUSSÃO}


Foram obtidos por simulação os diagramas de especiação metálica dos dois metais para as diferentes soluções. Na Figura 1, são apresentados os diagramas da prata para a
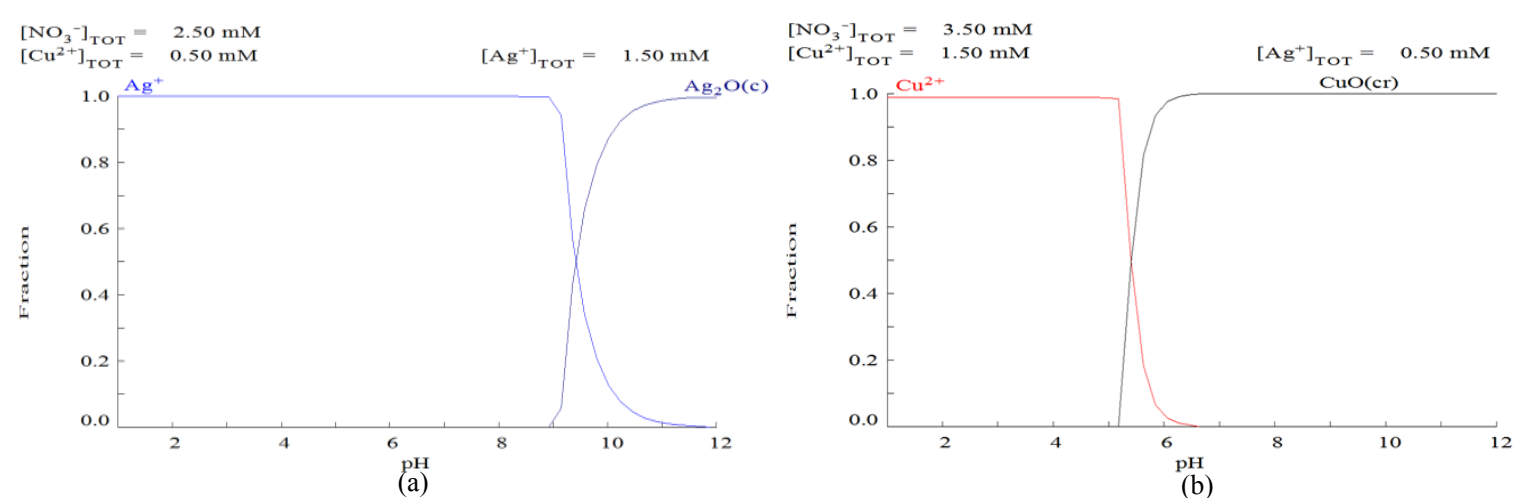

Solução 2 e o do cobre para a Solução 3, visto que estas são as soluções em que cada metal está presente em maior concentração e portanto, apresentaram as maiores restrições.

Figura 1 - Diagrama de especiação metálica da prata (a) e do cobre (b).

É possível observar por meio da Figura 1 que a concentração de íons de prata se manteve constante até um valor de $\mathrm{pH}$ próximo a 8,9 e para o cobre este valor foi próximo a 5,2. Desta forma, para que não houvesse formação de precipitados, os experimentos de cinética foram realizados em $\mathrm{pH}$ inferior a 5. Contudo, estes resultados obtidos para a especiação estão baseados nas soluções com os íons sem a presença da argila e, portanto, podem diferir da realidade. soluções.

A Figura 2 apresenta as curvas cinéticas da prata e do cobre em mistura para todas as

Figura 2 - Curvas cinéticas das soluções 1,2 e 3

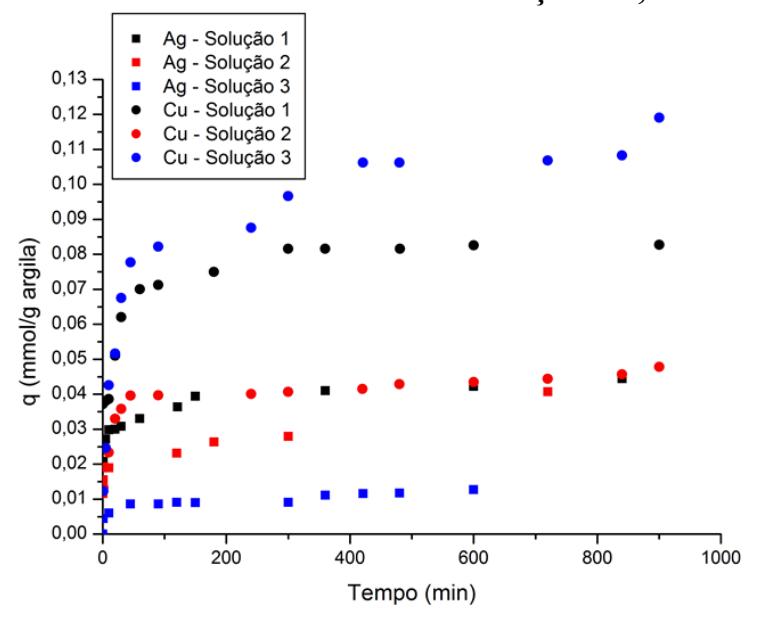

A análise do gráfico da Figura 2 permite observar que um tempo de experimento de 400 minutos foi suficiente para que o equilíbrio fosse atingido. Notou-se também que a adsorção do cobre na argila Verde-lodo é maior que a da prata quando os dois se encontram em solução bicomposta, visto que na solução 1, que apresentava a mesma concentração dos dois metais, o cobre teve uma adsorção muito superior. Isto também pode ser observado comparando-se as soluções 2 e 3, onde a adsorção do cobre na solução 3, que estava em 


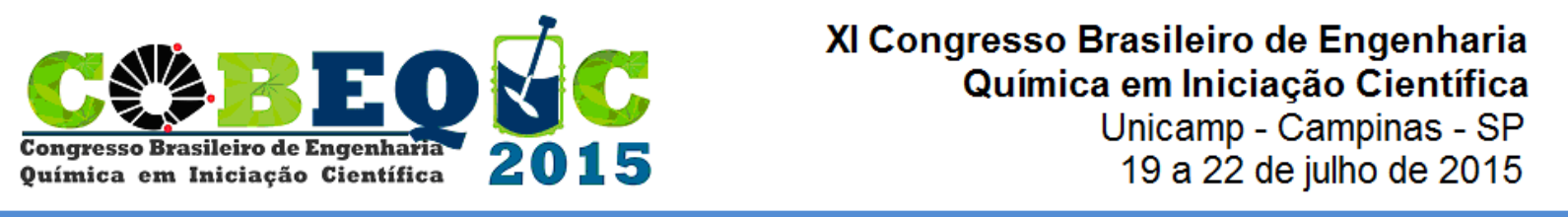

concentração de $1,5 \mathrm{mmol} / \mathrm{L}$ foi superior a da prata na solução 2 , que também estava na concentração de $1,5 \mathrm{mmol} / \mathrm{L}$.

A comparação dos resultados obtidos neste experimento com os trabalhos de Almeida Neto (2011) e Cantuaria (2014) permite observar que quando estes íons se encontram em solução bicomposta, a adsorção do cobre é favorecida e a da prata prejudicada, quando comparada com a adsorção dos íons em solução isolada. Tal fato pode ser explicado devido à existência de uma competição pelos sítios ativos do adsorvente, quando os dois metais estão em solução. Além disso, pelos resultados observados, pode-se supor a ocorrência de uma inibição da adsorção da prata na presença de cobre.

Após a realização do experimento de cinética, efetuou-se a modelagem matemática dos dados a partir dos ajustes dos modelos cinéticos para as soluções 1,2 e 3 . A Figura 3 apresenta de forma ilustrativa para as demais curvas os ajustes obtidos para a cinética da Solução 1 (concentrações 1,0 e 1,0 mmol/L para $\mathrm{Ag} \mathrm{e} \mathrm{Cu}$ ).

Figura 3 - Ajustes das curvas cinéticas da Solução 1 nos modelos: (a) Pseudoprimeira ordem e pseudossegunda ordem; (b) Difusão Intrapartícula; (c) Modelo de Boyd para a Ag; (d) Modelo de Boyd para o $\mathrm{Cu}$.

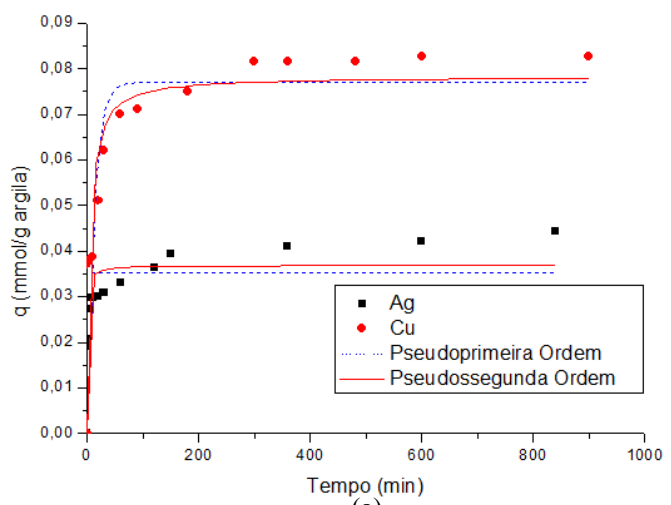

(a)

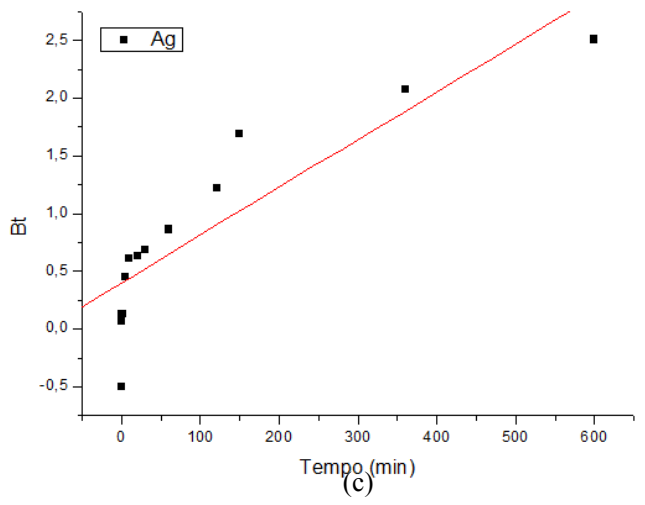

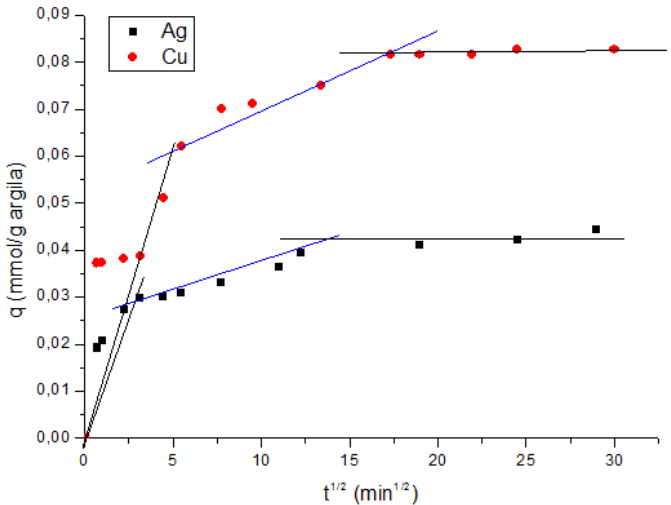

(b)

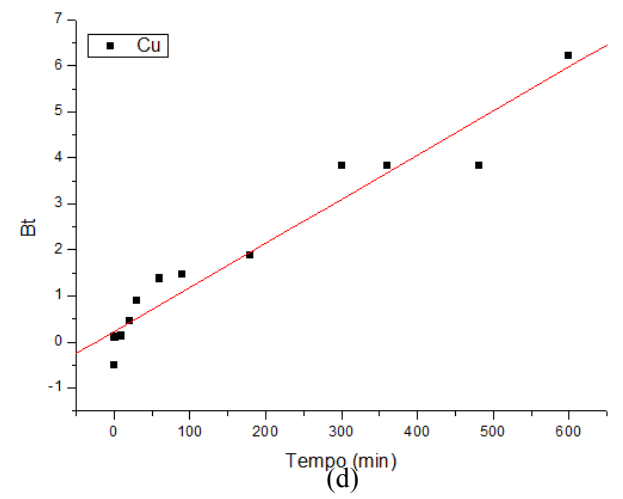

A Tabela 1 apresenta os valores dos coeficientes de determinação $\mathrm{R}^{2}$ de cada modelo utilizado, as constantes das taxas de remoção $\mathrm{k}_{\mathrm{i}}, \mathrm{k}_{1}$ e $\mathrm{k}_{2}$, a quantidade de íon metálico adsorvido no sólido no equilíbrio $\mathrm{q}_{\mathrm{e}}$ para os modelos de pseudoprimeira ordem e pseudossegunda ordem, os valores experimentais da quantidade de íon metálico adsorvido no equilíbrio $\mathrm{q}_{\mathrm{exp}}$, o valor de $\mathrm{c}$ do Modelo de Difusão Intrapartícula, que está relacionado à espessura da camada limite, o Desvio Médio Relativo (DMR), que pode ser calculado através 
da equação $D M R=\left(q_{e}-q_{\exp }\right) / q_{e}$ e por fim, para o modelo de Boyd é apresentado também o valor da difusividade Di.

Tabela 1 - Parâmetros dos modelos cinéticos para a adsorção da prata e cobre

\begin{tabular}{|c|c|c|c|c|c|c|c|}
\hline \multirow{3}{*}{ Modelo } & \multirow{3}{*}{ Parâmetro } & \multicolumn{6}{|c|}{ Solução } \\
\hline & & \multicolumn{2}{|c|}{1} & \multicolumn{2}{|c|}{2} & \multicolumn{2}{|c|}{3} \\
\hline & & $\mathrm{Ag}$ & $\mathrm{Cu}$ & $\mathrm{Ag}$ & $\mathrm{Cu}$ & $\mathrm{Ag}$ & $\mathrm{Cu}$ \\
\hline Experimental & qe $(\mathrm{mmol} / \mathrm{g})$ & 0,040 & 0,082 & 0,045 & 0,034 & 0,010 & 0,110 \\
\hline \multirow{4}{*}{$\begin{array}{c}\text { Pseudoprimeira } \\
\text { ordem }\end{array}$} & qe $(\mathrm{mmol} / \mathrm{g})$ & 0,035 & 0,077 & 0,038 & 0,032 & 0,010 & 0,099 \\
\hline & $\mathrm{k} 1\left(\min ^{-1}\right)$ & 1,121 & 0,081 & 0,116 & 0,024 & 0,109 & 0,039 \\
\hline & $\mathrm{R}^{2}$ & 0,795 & 0,682 & 0,754 & 0,898 & 0,774 & 0,954 \\
\hline & $\operatorname{DMR}(\%)$ & 15,60 & 21,74 & 21,68 & 20,84 & 19,47 & 15,04 \\
\hline \multirow{4}{*}{$\begin{array}{l}\text { Pseudossegunda } \\
\text { ordem }\end{array}$} & qe $(\mathrm{mmol} / \mathrm{g})$ & 0,037 & 0,078 & 0,041 & 0,034 & 0,011 & 0,106 \\
\hline & k2 (g/mmol.min) & 34,80 & 2,549 & 2,567 & 1,246 & 15,95 & 0,0528 \\
\hline & $\mathrm{R}^{2}$ & 0,859 & 0,769 & 0,821 & 0,954 & 0,834 & 0,982 \\
\hline & $\operatorname{DMR}(\%)$ & 12,51 & 17,98 & 20,41 & 15,11 & 16,62 & 9,45 \\
\hline \multirow{4}{*}{$\begin{array}{c}\text { Difusão } \\
\text { Intrapartícula }\end{array}$} & ki (mmol/g.min) & 0,0011 & 0,0015 & 0,0012 & 0,0014 & 0,00041 & 0,0019 \\
\hline & $\mathrm{c}(\mathrm{mmol} / \mathrm{g})$ & 0,026 & 0,056 & 0,019 & 0,011 & 0,005 & 0,063 \\
\hline & $\mathrm{R}^{2}$ & 0,979 & 0,968 & 0,959 & 0,986 & 0,937 & 0,956 \\
\hline & DMR (\%) & 11,47 & 21,47 & 13,12 & 36,14 & 11,21 & 57,48 \\
\hline \multirow{2}{*}{ Modelo de Boyd } & $\mathrm{Di}\left(\mathrm{cm}^{2} / \mathrm{min}\right)$ & $3,1 \mathrm{E}-06$ & 7,1E-06 & $3,7 \mathrm{E}-06$ & $1,2 \mathrm{E}-5$ & 9,1E-08 & $3,5 \mathrm{E}-06$ \\
\hline & $\mathrm{R}^{2}$ & 0,883 & 0,972 & 0,967 & 0,964 & 0,816 & 0,954 \\
\hline
\end{tabular}

O modelo de pseudoprimeira ordem não descreve adequadamente o número de sítios ativos disponíveis do adsorvente (Cantuaria, 2014), o que explica os baixos valores dos coeficientes de determinação para este modelo em vista do modelo de pseudossegunda ordem, que por este motivo apresentou um melhor ajuste. Os valores de k1 e k2 representam a velocidade da reação, tendo uma relação diretamente proporcional com a velocidade de adsorção. Analisando-se o valor de k1, não se observa grande influência da concentração inicial da solução. Porém, no caso de $\mathrm{k} 2$, tal grandeza é diretamente influenciada pela concentração inicial, sendo maior para a maior concentração inicial, ao se considerar a prata; e menor quando a concentração é maior, para o cobre.

O modelo de difusão intrapartícula foi o que melhor ajustou os dados do cobre e da prata, como pode ser observado pelos valores de $\mathrm{R}^{2}$. Porém, tais valores de $\mathrm{R}^{2}$ não podem ser comparados aos demais modelos, uma vez que considera apenas uma faixa de valores de dados experimentais. Nas curvas de q vs. $\mathrm{t}^{1 / 2}$ fornecidas por esse ajuste, observam-se três fases distintas, onde na primeira ocorre a difusão na superfície externa, na segunda há a difusão intrapartícula e na terceira o equilíbrio é atingido. Observa-se também que os valores de Ki são baixos para todas as concentrações.

A titulação potenciométrica permitiu o cálculo da densidade de carga do adsorvente e a construção de um gráfico deste valor em função do $\mathrm{pH}$, que se encontra na Figura 4. A análise desse gráfico permite concluir que o valor do $\mathrm{pH}_{\mathrm{ZPC}}$ da argila Verde-lodo calcinada, contaminada ou não, é próximo de 5,3, visto que é nesse $\mathrm{pH}$ que a argila possui carga 


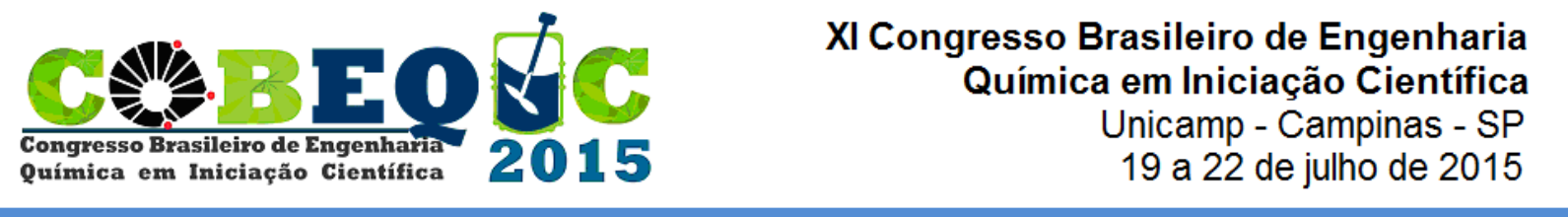

superficial nula. Abaixo desse valor, o sólido será carregado positivamente e acima, negativamente.

Figura 4 - Densidade de Carga da argila Verde-lodo calcinada, contaminada e não contaminada, em função do $\mathrm{pH}$

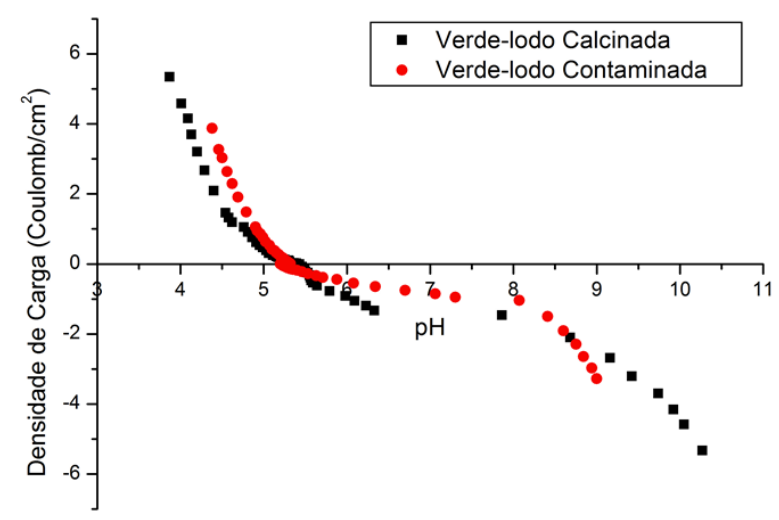

Como todos os ensaios de cinética foram realizados em $\mathrm{pH}$ inferior a 5 , onde a argila apresenta carga superficial positiva, a adsorção dos metais pode ter sido desfavorecida, já que estes também são positivamente carregados.

\section{CONCLUSÕES}

Verificou-se no estudo da cinética em sistema bicomposto que o cobre apresenta maior capacidade adsortiva, quando em presença da prata, enquanto esta é inibida pela presença do cobre. Dos modelos ajustados, o que melhor descreveu a adsorção do cobre foi o de difusão intrapartícula, enquanto para a prata foi o modelo de pseudossegunda ordem.

\section{AGRADECIMENTOS}

Os autores agradecem à FAPESP (Proc. n. 2013/00732-1 e 2013/25212-0) e ao CNPq pelo apoio financeiro.

\section{REFERÊNCIAS}

AGUIAR, M. R. M. P. de; NOVAES, A. C.; GUARINO, A. W. S. Remoção de metais pesados de efluentes industriais por aluminossilicatos. Quím. Nova [online], vol.25, n.6b, pp. 1145-1154, 2002.

ALMEIDA NETO, A. F., Caracterização e avaliação de argilas como adsorventes na remoção e eluição de íons cobre e mercúrio em diferentes sistemas. Tese (Doutorado) - Faculdade de Engenharia Química, Universidade Estadual de Campinas, Campinas, 2011.

CANTUARIA, M. L. Remoção de prata iônica monovalente por adsorção em argila bentonítica. Dissertação (Mestrado). Faculdade de Engenharia Química, Universidade Estadual de Campinas, Campinas, 2014.

JIMENEZ, R. S.; DAL BOSCO, S. M.; CARVALHO, W. A. Remoção de metais pesados de efluentes aquosos pela zeólita natural escolecita - influência da temperatura e do pH na adsorção em sistemas monoelementares. Quím. Nova, São Paulo, v. 27, n. 5, 2004 . 